\title{
En torno al 2001 en la narrativa argentina*
}

\author{
Sylvia Saítta**
}

\begin{abstract}
Resumen
El artículo propone un panorama de la narrativa argentina de finales del siglo veinte y comienzos del veintiuno con la hipótesis de que aun en tiempos de globalización, postautonomía e internacionalización del mercado editorial es posible trazar líneas de inscripción y diálogo entre la nueva narrativa y las grandes tradiciones de la literatura argentina.
\end{abstract}

Palabras clave: Narrativa argentina, década del noventa, historia literaria argentina.

\section{Around 2001 in Argentinien narrative}

\begin{abstract}
The article proposes an overview of Argentinien narrative at the end of the twentieth century and early in the twenty-first. The main hypothesis of the research is that, even in times of globalization, postautonomia and internationalization of the publishing market, is possible to draw lines of dialogue between the new narrative and the great traditions of Argentinien literature.
\end{abstract}

Key words: Argentinien Literature, the 90 's, argentinien literary history.

Recibido: 22-05-2013 Aceptado: 05-09-2013

* Una versión de este trabajo se publicó bajo el título "Die argentinische Erzählliteratur" en Klaus Bodemer, Andrea Pagni und Peter Waldmann (comps.), Argentinien heute. Politik, Wirtschaft, Kultur, Vervuert Verlag, Frankfurt am Main, 2010. Se inscribe en el marco del proyecto Ubacyt "Itinerarios periodísticos de intelectuales y escritores argentinos", Universidad de Buenos Aires, 2011.

** Argentina, Doctora en Letras, Universidad de Buenos Aires, CONICET, Buenos Aires, Argentina, sylviasaitta@gmail.com 
Recién comenzado, el nuevo milenio reveló a los argentinos que las promesas de bienestar económico y modernización acelerada abiertas por el gobierno de Carlos Saúl Menem habían llegado a su fin. La violenta crisis económica, social y política de diciembre de 2001, cuando vastos sectores de la clase media salieron con sus cacerolas a la calle, los piqueteros cortaron las rutas, las asambleas populares gritaron "que se vayan todos" y el presidente Fernando de la Rúa abandonó la Casa Rosada en helicóptero, marcó el fracaso de las políticas neoliberales de reforma del Estado que habían caracterizado a los años noventa: la privatización de las empresas de servicios públicos, la concentración del ingreso, la desregulación de las actividades económicas, las políticas de ajuste traducidas en reducción de salarios, precarización del trabajo y altas tasas de desempleo. Esos días de diciembre de 2001 clausuraron el imaginario de los años noventa — cuya formulación periodística fue la de la fiesta menemista de "pizza con champagne" - y pusieron en primer plano un presente signado por la exclusión social, la desocupación, la marginalidad urbana, la disgregación social, aspectos que pasaron a ser tema de una parte importante de la literatura argentina escrita en el período. Como sostuvo Daniel Link, la cultura argentina de finales del siglo veinte se vio sometida a una doble violencia: la de un pasado dictatorial traumático y la de "los restos de las fantasías neoliberales, que pretendieron construir una cultura 'nueva', una cultura 'moderna' sobre ruinas que, en esas fantasías, sólo tenían un valor de cambio determinado" (Link, 2003: 16).

Fue también durante los años noventa cuando se instauraron procesos de globalización económica que crearon un nuevo orden cultural que modificó los contenidos y las fronteras culturales de los Estados nacionales; en palabras de Néstor García Canclini, las identidades culturales tradicionales y modernas, de base territorial (Estado-nación), dieron paso a las identidades posmodernas, de carácter transterritorial (García Canclini, 2001). El impacto en las literaturas nacionales fue profundo: los consorcios editoriales transnacionales, que fusionaron casas editoras de diversos países, subordinaron la producción de cada nación a la programación de una política de bestsellerización, y modificaron las estructuras de distribución y de venta de los libros. Como describe André Schiffrin, uno de los más notables editores independientes, los consorcios pasaron a elegir los libros que produjeran mayores ganancias; por lo tanto, la decisión de publicar o no un libro "ya no la toman los 
editores sino lo que se llama el comité editorial, donde el papel principal lo desempeñan los responsables financieros y los comerciales" (Schiffrin, 2001: 70). Producir literatura para un mercado global aceleró la rotación de los libros: se editaron más títulos que pronto fueron reemplazados por títulos aún más nuevos. Esta organización favoreció la circulación transnacional de libros concebidos para el mercado de masas: si bien siempre existieron los best sellers, la novedad radicó en la difusión de una narrativa destinada a la circulación internacional, a la que se denominó world fiction: una narrativa artificialmente fabricada, producto comercial destinado a una difusión amplia, según criterios y recetas ya experimentadas (Casanova, 2001).

Con la reestructuración de la industria del libro, y también a mediados de los noventa, se afianzaron las editoriales independientes, un espacio alternativo para textos que no se adecuaban a las exigencias del mercado. Se trató de editoriales de pequeña infraestructura, con títulos de tirada mediana o chica, cuya expectativa de venta oscila entre los setecientos y los mil ejemplares a lo largo de algunos años (Astutti y Contreras, 2001). Ciertos géneros narrativos o primeras novelas de escritores inéditos encontraron entonces su lugar en Beatriz Viterbo, Simurg, Adriana Hidalgo, Tierra Firme, Paradiso o Alción: libros de cuentos — dato por demás significativo en una literatura como la argentina, de larga y prestigiosa tradición en el género-; novelas de larga extensión —las mil trescientas páginas de Los Soria (1998) de Alberto Laiseca, por ejemplo, o las seiscientas de Las Islas (1998) de Carlos Gamerro-; primeros libros de escritores jóvenes que, en muchos casos, integraron después los catálogos de las grandes editoriales, como Gustavo Ferreyra, Martín Kohan, Aníbal Jarkovski, Juan José Becerra, Marcos Herrera, entre otros. A estas editoriales, se sumaron, después de la crisis económica de 2001, nuevos emprendimientos, entre los que sobresalieron Interzona, Mansalva, Entropía, Santiago Arcos, Eloísa Cartonera y Eterna Cadencia.

En este marco, la literatura argentina de los noventa se caracterizó por la irrupción de jóvenes escritores que renovaron, con sus revistas, sus polémicas, su alta visibilidad tanto en circuitos académicos como en los medios masivos, el mapa literario de los años ochenta presidido por Ricardo Piglia, Juan José Saer y Manuel Puig, los tres escritores que, en palabras de José Luis de Diego, consolidaron un lugar dominante en el campo literario argentino de la posdictadura. Mientras Piglia y Saer produjeron fuertes intervenciones de lectura y ordenamiento de la 
literatura argentina, Puig se mantuvo al margen de las rencillas locales pero su obra concitó un creciente interés entre los más jóvenes escritores y en la crítica académica (De Diego, 2001). No obstante, el peso de cada uno de ellos en el canon de la literatura argentina fue confirmado o cuestionado en el nuevo milenio. En el caso de Juan José Saer, la discusión se saldó a comienzos de siglo: como sostiene Julio Premat, si el reconocimiento y la lectura sistemática de sus obras se había producido durante los ochenta, es en el siglo veintiuno cuando "pasa a ser considerado como 'el mejor escritor argentino', 'uno de los más importantes de nuestro tiempo', situado en el "centro del canon", según se lee en contratapas, en artículos periodísticos o se oye en conversaciones con colegas de Buenos Aires" (Premat, 2003: 43). En esos años se confirma el lugar de Saer en el sistema literario argentino como lo demuestran la publicación de sus Cuentos Completos en 2001; la reedición de todos sus libros, tanto de los que habían permanecido agotados en las librerías durante años -Cicatrices, La mayor, Nadie nada nunca- como de aquellos que sólo se habían publicado en los comienzos de su carrera literaria -Palo y hueso, Unidad de lugar, La vuelta completa-; las compilaciones de artículos y ensayos hasta entonces dispersos en diarios y revistas como El concepto de ficción, La narración-objeto, Trabajos. Su muerte, el 11 de junio de 2005, y la publicación póstuma de su extraordinaria novela $L a$ grande en octubre de ese mismo año, lejos de cerrar un ciclo, colocaron a la narrativa de Juan José Saer en el centro del sistema literario. "La grande —afirma Carlos Gamerro- es la última novela de Saer, pero no su novela final" (Gamerro, 2005); "cerrado por la muerte de su autor —sostiene Beatriz Sarlo-, el ciclo novelístico es hoy precisamente eso: un anillo que gira pausadamente" (Sarlo, 2007). Y efectivamente, si en el sistema narrativo de Saer la aparición de una nueva novela o relato reescribía a los anteriores, la publicación de La grande crea nuevas figuraciones y nuevos sentidos de una obra que, como su última novela, permanecerá inacabada y abierta a lecturas futuras.

Muy diferente fue el posicionamiento de Piglia en la escena literaria argentina. Mientras la literatura de Saer fue leída, durante décadas, sólo por un conjunto de lectores iniciados, la publicación de Respiración artificial en 1980 — considerada por muchos críticos como la novela más representativa de la literatura argentina escrita durante la dictadura-, convirtió a Piglia en una suerte de referente generacional, rápidamente consagrado por la crítica y sus pares literarios. Como analiza De Diego, 
Piglia pivotea en el centro del campo literario de los ochenta porque sus operaciones críticas de canonización de los escritores del pasado (Jorge Luis Borges, Roberto Arlt y Rodolfo Walsh) y de canonización de algunos de sus contemporáneos (Saer, Puig) se instalaron en el debate literario "como verdades incontrastables" (De Diego, 2001: 220). La publicación de Prisión perpetua en 1988 y La ciudad ausente en 1992, sumada al estreno de la ópera basada en esta última novela, con música de Gerardo Gandini, en 1995, ratificaron su posición como escritor y como crítico en el centro del escenario. Si bien el escándalo mediático y judicial que desencadenó la obtención del Premio Planeta en noviembre de 1997 por su novela Plata quemada, mantuvo a Piglia en el centro no sólo del sistema literario sino, y sobre todo, del cotilleo periodístico durante más de diez años, ${ }^{1}$ desde entonces su figura se impuso también en el ámbito internacional. A partir de 1999, cuando la editorial Anagrama dio inicio, con su libro de ensayos Formas breves, a la publicación de toda su obra en España, los textos de Piglia accedieron al mercado internacional y ubicaron a su autor como uno de los grandes renovadores de la literatura en lengua española, junto a Roberto Bolaño o Juan Villoro. Que en abril de 2008, Casa de América, en Madrid, le dedicara la Semana de Autor a Ricardo Piglia, en la cual críticos españoles y latinoamericanos analizaron su obra y reflexionaron sobre su impacto en las artes escénicas y cinematográficas; que a lo largo de esa semana se presentara el volumen de ensayos críticos y entrevistas El lugar de Piglia. Crítica sin ficción, editado por Jorge Carrión (2008); y que a la semana siguiente, fuese el mismo Piglia el que inauguró la Feria del Libro de Buenos Aires, son señales concluyentes de su consagración nacional e internacional.

Frente a la consagración de Piglia, la disidencia que César Aira había comenzado ya con la temprana publicación de una nota sobre Respiración artificial en 1981 en la revista Vigencia, continuó con Fogwill en los años

1 En noviembre de 1997, Ricardo Piglia recibió el Premio Planeta por su novela Plata quemada, por decisión unánime de un jurado integrado por Augusto Roa Bastos, Mario Benedetti, Tomás Eloy Martínez, María Esther de Miguel. Una nota publicada por Claudia Acuña en la revista Trespuntos cuestionó la legitimidad del resultado; el escritor Gustavo Nielsen, finalista del Premio Planeta, inició la demanda de un juicio que se resolvió en febrero de 2005 con un fallo que sostuvo que "existen demostradas muchas circunstancias que revelan la predisposición o predeterminación del premio en favor de la obra de Ricardo Piglia". Al fallo le siguieron numerosas notas periodísticas, acusaciones cruzadas entre sus protagonistas y una solicitada firmada por importantes escritores e intelectuales argentinos, que se publicó en diarios nacionales e internacionales, en solidaridad con Piglia por "la campaña de difamación" abierta en 1997 en la que "se lo acusa de ser quien es en nuestra literatura, en la cultura nacional y en el plano internacional y académico". 
noventa. Ambos escritores proponen narrativas que, con sus enormes diferencias, coinciden en ubicarse por fuera de los paradigmas estéticoideológicos dominantes en los años ochenta. Desde sus comienzos, Aira puso en funcionamiento una máquina de narrar despreocupada por el verosímil, librada a la improvisación y a la espontaneidad. Cada uno de sus libros, publicados uno tras otro y en diferentes sellos editoriales, no es sino la variación de un proyecto narrativo único diseñado a partir de la repetición y la variación de motivos, narradores, temas, géneros y estilos. En el trasfondo de sus tramas disparatadas, donde los hechos se suceden como sumas de errores, desatinos y malentendidos, aparece siempre la reflexión, irónica e incisiva, sobre los vínculos entre una subjetividad que percibe y el mundo percibido, sobre los límites del realismo como estética, sobre cierto tipo de crítica literaria que encuentra sus claves de lectura en lo social o en la biografía del autor (Contreras, 2002). Si la construcción de un personaje narrador es la suma de cierto número de efectos descriptivos diseminados en el enunciado, Aira desarticula la unidad de ese narrador que, en primera persona y en sucesivas novelas, no se define ni por su referencia ni por su nombre propio. En Cómo me hice monja (1993), por ejemplo, el narrador en primera persona no sólo muere al final del relato sino que se llama César Aira pero habla de sí mismo usando indistintamente los géneros femenino y masculino; en El Congreso de Literatura (1998), el clon de una avispa que no puede distinguir entre la ropa que usa Carlos Fuentes y el propio Carlos Fuentes funciona como metáfora del crítico literario que confunde dónde termina el escritor y dónde empiezan sus libros, y desarma todo intento de filiar los sucesos de todos los días al universo literario de la pura invención. Es en El llanto, donde Aira define una concepción de la literatura como aparato narrativo que, sin interrumpirse, viola todas las reglas del relato realista: "Por un lado está la panoplia de las artes. Enfrente están los objetos discretos del mundo. Sólo se trata de hacer coincidir ambas series. Pero como ya se ha hecho tanto arte, y hay tanto arte ya hecho, tantas coincidencias ya coincididas, hoy día parece como si no pudiera haber arte en proceso sino allí donde no hay coincidencia, donde hay una inadecuación disonante y sorpresiva" (Aira, 1992). Enfrentada a un arte que se piensa como la coincidencia con lo real, la literatura de Aira se propone, precisamente, como "una inadecuación disonante y sorpresiva" con la realidad. Esta inadecuación rige tanto el verosímil de la trama como la construcción de las frases, donde abundan oraciones 
paradójicas que admiten dos sentidos a la vez, sin decidirse por ninguno. "Nadie que no fuera un mago de verdad, podría permitirse el lujo de la creación de algo tan frívolo como esta comedieta triste" (Aira, 2003), sostiene el narrador de El mago, después de la transcripción de un disparatado diálogo entre los objetos del baño; nadie que no sea un escritor "de verdad", como lo es César Aira, podría "permitirse el lujo" de publicar textos que, bajo la apariencia de la frivolidad y la ligereza, no son sino las distintas modulaciones de un proyecto narrativo original y único en la literatura argentina.

Fogwill, en cambio, propuso una vuelta al realismo: sus últimas novelas -la trilogía formada por Vivir afuera (1998), La experiencia sensible (2000) y En otro orden de cosas (2001) — son una reflexión, cínica y aguda a la vez, del contexto socio-político de la década menemista afirmando, de este modo, las posibilidades del realismo en una literatura como la argentina que, bajo la impronta borgeana, apostaba por la no representación de lo real, el uso de la cita, el estilo conjetural y la exhibición de la desconfianza que genera la lengua como medio para representar la realidad. En este sentido, Karina Vázquez sostiene que Fogwill incorporó a la narrativa argentina de finales de los años noventa un paradigma para pensar la política desde la literatura que reemplazó el inaugurado por Piglia en los ochenta: con la trilogía, se canceló la centralidad de las técnicas alusivas y se puso el acento en las representaciones de la realidad social (Vázquez, 2009). Lejos del desprecio por lo real, la narrativa de Fogwill se caracteriza por una apuesta realista que encuentra en la nominación detallada de los objetos a través de sus marcas comerciales y en el realismo de la lengua con la que hablan sus personajes sus procedimientos más evidentes. Este programa es el que se lee en la "Presentación del autor" que antecede a Cantos de marineros en La Pampa (1998) —edición que compila sus cuentos y Los pichiciegos para el público español—, donde sostiene: "Sé que no he escrito una sola página que me atreva a publicar que no proceda del dictado de una voz. (...) No he escrito nada que merezca atención sin haber estado sintiendo en el curso de su copia al dictado alguna emoción del orden de la hostilidad, el rencor, la rabia, el odio, la envidia y la indignación: formas confusas del conflicto social que anuncian algo muy vago. A veces me creo a un paso de comprenderlo y fracaso. Ahora pienso que no dejaré de escribir hasta saber que he dado cuenta de ello" (Fogwill, 1998). Las voces que "dictan" aumentan el "efecto de realidad" de novelas que son el entramado de lenguas diversas a través de las 
cuales ingresa lo social. En las inflexiones del habla, a través de las cuales se construyen los personajes - los personajes en Fogwill son la lengua que hablan-, ingresan las prácticas sociales: la lengua de una picaresca de la guerra en Los pichiciegos; las lenguas marginales de la droga, la prostitución y el delito en Vivir afuera; el discurso bienpensante de la izquierda progresista, los lenguajes degradados de los medios masivos y el discurso oficial del Estado.

No obstante, no es Fogwill un caso aislado en la narrativa argentina de comienzos de siglo. Varios críticos literarios sostienen que a finales del siglo veinte se produjo una "vuelta al realismo" que cuestionó la centralidad de la literatura alusiva y anti-realista que caracterizó a la narrativa durantelos años ochenta (Speranza, 2005; Kohan 2005; Contreras, 2006). María Teresa Gramuglio fue una de las primeras críticas en señalar que, a partir de 1995, con la publicación de Villa de Luis Gusmán, se produjo una torsión en la tradición de relatos sobre la dictadura: el fin de la alusión y la oblicuidad y una "vuelta al realismo", una aproximación a cierta mimesis y a la vez, la puesta en escena de voces de torturadores y cómplices que instalan el problema del consentimiento civil (Gramuglio, 2002). Miguel Dalmaroni retomó las hipótesis de Gramuglio para afirmar que a mediados de los noventa una suma de acontecimientos políticos -la admisión del secuestro, la tortura y el asesinato por parte de los genocidas de la ESMA Juan Carlos Rolón y Antonio Pernías en el Senado de la Nación, en 1994; la publicación de El vuelo de Horacio Verbistky, en 1995, con las confesiones del ex capitán de corbeta Adolfo Scilingo; la creación de la red nacional de agrupaciones de HIJOS de detenidosdesaparecidos, en 1995 - creó la condiciones político-discursivas de una nueva fase de la postdictadura con la emergencia de nuevas narrativas de la memoria del horror, distinguibles de una fase anterior, signada por el informe Nunca más de la CONADEP y por el juicio a las juntas militares de 1985 (Dalmaroni, 2004). Se trata de una "nueva novelística sobre la dictadura" que contrasta con las narraciones de los ochenta porque abandonaron el relato cifrado para apostar por la construcción de una trama y una vuelta a ciertos procedimientos del realismo. Tanto en "la posibilidad de narrar refiriendo por completo, y de modo directo, los sucesos y acciones más atroces o inenarrables" (Dalmaroni, 2004: 159), como en la incorporación de otras voces destinadas a dar cuenta de la dictadura, esta nueva narrativa reflexiona sobre cómo recuperar desde otro lugar la memoria y la identidad colectiva. 
A partir de Villa de Gusmán otras problemáticas interesaron a la narrativa argentina: con la historia de un oscuro médico del ministerio de Bienestar Social, encargado de revivir a los torturados o de firmar certificados de defunción durante la gestión de López Rega y los comienzos de la dictadura militar, se produjo el viraje subrayado por Gramuglio: si la narrativa de los ochenta había comprobado la responsabilidad política del gobierno militar, la nueva narrativa se ocupó, en cambio, del lugar, las culpas y la responsabilidad de la población civil en el terrorismo de Estado. Como analiza Hugo Vezzetti en Pasado y presente, la barbarización, la política y la degradación del Estado no hubieran sido posibles sin el compromiso, la adhesión, la conformidad de muchos: "la trama de relaciones, complicidades, oportunismos, no puede estar ausente en una exploración de la memoria en la medida en que, precisamente, constituye el punto ciego de una recuperación que vuelva sobre las responsabilidades de la sociedad" (Vezzetti, 2002).

Dos veces junio (2002) de Martín Kohan retoma de Villa la representación de los cómplices civiles de la dictadura militar para explorar la constitución de una subjetividad al servicio del régimen y las condiciones que hicieron posible el surgimiento y la legitimidad de su dominio político; a través de la figura de un conscripto al servicio de un médico del ejército la novela reflexiona sobre las instancias de aprendizaje de una sociedad militarizada por parte de dos de sus instituciones clave: la escuela y la familia. Por su parte, El secreto y las voces (2002) de Carlos Gamerro, narra la trama de lealtades y complicidades entre el poder militar y los habitantes de un pequeño pueblo de provincia, para indagar sobre los motivos, intereses, ideas y creencias a través de los cuales se legitimó el crimen de Estado.

También la literatura argentina imaginó los sueños de venganza y de justicia por mano propia de los integrantes de una sociedad descreída de la justicia a partir de la situación de impunidad legal que favoreció a los represores después de las sucesivas leyes de Obediencia Debida, Punto Final e indulto que dejaron en libertad a cientos de torturadores y asesinos. Calle de las Escuelas $N^{o} 13$ de Martín Prieto (1999) y Bajo el mismo cielo de Silvia Silberstein (2002) son, en términos de Gramuglio, "una especie de formación compensatoria literaria" que buscan corregir el déficit de la justicia legal. Mientras en Calle de las Escuelas $N^{o} 13$, un grupo de jóvenes tiene el proyecto, fracasado, de asociarse para matar a un torturador y ejercer así una venganza justiciera en contra de los 
liberados de la dictadura; en Bajo el mismo cielo, un sobreviviente busca infructuosamente vengar de alguna manera el secuestro, la desaparición y la muerte de su mujer en la Escuela de Mecánica de la Armada.

A su vez, novelas como Los planetas (1999) de Sergio Chejfec, Ni muerto has perdido de tu nombre (2002) de Luis Gusmán, Ciencias morales (2007) de Martín Kohan, o 1976 (2008) de Félix Bruzzone, realizan un trabajo de ficcionalización de la memoria social que, alejadas tanto de una voluntad reconstructiva como del panfleto de denuncia, problematizan los vínculos del presente con el pasado y la presencia del pasado en el presente. Son, en términos de José di Marco, "ficciones que hacen memoria" pues participan de una corriente social y de un conjunto de prácticas fragmentarias que tienden a trazar la línea de continuidad entre el pasado y el presente (Di Marco, 2003). Los topos (2008) de Bruzzone, exaspera el trabajo sobre la ficción ubicándose por fuera de las narrativas de la memoria y del testimonio. Siendo él mismo un hijo de desaparecidos, Bruzzone abandona la posición políticamente correcta sobre el tema de los desaparecidos para narrar la historia de un hijo de desaparecidos criado por su abuela, que se enamora de un travesti, también hijo de desaparecidos, cuyo proyecto es matar represores, y que desaparece en tiempos democráticos.

Vinculada a la literatura de la dictadura, a mediados de los años noventa emergió una narrativa sobre la militancia de los años setenta: si en los comienzos de la democracia se privilegió el carácter de víctimas de los desaparecidos y los sobrevivientes, y quedó obturada asíla posibilidad de narrar los acontecimientos sociales y políticos de la primera mitad de la década del setenta, en los noventa se retoma su pasado revolucionario. En marzo de 1996, cuando se cumplieron los veinte años del golpe militar, se estrenó el documental Cazadores de Utopías, dirigido por David Blaustein, con testimonios de militantes y ex-militantes políticos, que produjo una gran polémica sobre la militancia, la responsabilidad de los montoneros, la lucha armada, el horizonte ideológico de los años setenta (Sonderéguer, 2001). Al año siguiente, también en marzo, se publicó El presidente que no fue. Los archivos ocultos del peronismo, la historia de la vida y la presidencia de Héctor Cámpora, de Miguel Bonasso, y el primer tomo de la monumental obra de Eduardo Anguita y Martín Caparrós, La voluntad (editados en marzo de 1997, octubre de 1997 y marzo de 1998), que construye una historia de la militancia revolucionaria en Argentina entre 1966 y 1978, a través de los relatos de sus principales protagonistas 
y una exhaustiva investigación del período. Ambas publicaciones fueron tema de debate en dos de las publicaciones intelectuales más prestigiosas del país: el número de agosto de 1997 de Punto de Vista, dirigida por Beatriz Sarlo (donde escribieron Terán, Hugo Vezzetti, Sarlo, Emilio de Ípola, Raúl Beceyro) y dos números del mismo año de Confines, dirigida por Nicolás Casullo (en los que escribieron Nicolás Casullo, Héctor Schmucler, Ricardo Forster, Gregorio Kaminsky, Matías Bruera, Alejandro Kaufman, Oscar Del Barco) pusieron su centro en la reflexión sobre la militancia revolucionaria. Desde entonces numerosas autobiografías y testimonios volvieron al relato de la propia experiencia, confiando en la potencia narrativa del recuerdo y en la memoria para reconstruir el pasado. En Tiempo pasado. Cultura de la memoria y giro subjetivo (2005), Beatriz Sarlo criticó este giro subjetivo que, a pesar del descrédito teórico de la primera persona, confía en el testimonio como herramienta fiable de conocimiento.

La literatura también volvió su mirada a la militancia de los años setenta. En 1996, Liliana Heker desató la polémica con la publicación de El fin de la historia, cuya protagonista — que remite a un caso verdaderoes una oficial montonera presa en la ESMA que, trabajando para el "mini-staff" del general Massera, se enamora del hombre que la torturó, con quien se fuga a Europa al final de la dictadura. ${ }^{2}$ El texto exponía, en términos ficcionales, dos hipótesis recurrentes en el debate sobre la militancia de los setenta y sobre las que Ana Longoni reflexionó en Traiciones (2007): la que lee el "quiebre" de una guerrillera bajo tortura en términos de traición, y la que considera traidor al que sobrevivió a la represión. Otras novelas, en cambio, como Memorias del río inmóvil (2001) de Cristina Feijóo, Museo de la revolución (2006) de Martín Kohan, Historia del llanto (2007) de Alan Pauls, volvieron a las experiencias revolucionarias de los setenta para trazar un arco con los noventa y mostrar la continuidad entre la guerra sucia y las políticas de vaciamiento ideológico del neoliberalismo.

Después de la nulidad de las "leyes de impunidad" en 2003, que marca el momento de consolidación de la "política de la memoria" del gobierno de Néstor Kirchner, la literatura vuelve a la militancia de los años setenta

2 Para una descripción comentada de esta polémica, véase Rogelio Demarchi, 2003. 
pero para corroer los mitos fundacionales de la lucha revolucionaria y quebrar el automatismo de las consignas revolucionarias y la retórica de las organizaciones armadas. La vida por Perón (2004) de Daniel Guebel, La aventura de los bustos de Eva (2004) de Carlos Gamerro, Las teorías salvajes (2008) de Pola Oloixarac, cuentan nuevamente la historia de la militancia pero por fuera de cualquier tono heroico y en clave de absurdo, apelando a los procedimientos de la parodia, el grotesco, la picaresca y la farsa.

Como se señaló, el 2001 marcó el comienzo de un nuevo ciclo político, económico y social en la historia argentina. El rápido empobrecimiento de una parte importante de la clase media marcó un corte abrupto con el modelo histórico-cultural hasta entonces vigente. La caída económica, sostienen Víctor Armony y Gabriel Kessler, marcó el fin del proceso de reproducción del sentido de la trayectoria social familiar, sostenido por el ideal de una movilidad ascendente de cada generación respecto a la que la antecedía (Armony y Kessler, 2004). Esta clase media empobrecida salió a la calle y participó de las asambleas barriales mientras que los más pobres - cuya cara más visible fue la que conformaron los piqueterosimplementaron formas de acción directas — corte de rutas, autopistas y calles de la ciudad-que movilizaron a grandes contingentes.

La literatura escrita en estos años volvió su mirada a la sociedad como si recién la descubriera; representó un paisaje urbano fuertemente polarizado entre la abundancia de sus barrios más ricos y la carencia de los cartoneros que recorrían sus calles. La narrativa incorporó entonces el violento escenario socio-cultural abierto en los finales de la década menemista, para poner su acento en la representación de los procesos que condujeron a la pauperización de vastos sectores de la población. Vértice (2004) de Gustavo Ferreyra, por ejemplo, revela una ciudad invadida por el miedo y la percepción paranoica del otro social a través de una trama centrada en la irrupción de un chico de la calle pidiendo monedas en uno de los barrios acomodados de la ciudad; El trabajo (2007) de Aníbal Jarkowski, retomó el proyecto de literatura social para narrar, de modo impiadoso y distanciado, la humillación y el despojo de la desocupación y el abuso laboral. En Puerto Apache (2002) de Juan Martini, Promesas y desvaríos (2004) de Griselda Gambaro y Rabia (2005) de Sergio Bizzio, se narra el mundo de la pobreza sin apelar a los facilismos del panfleto de denuncia o a los procedimientos más clásicos del realismo social. 
En este marco, la literatura de los más jóvenes reprodujo el movimiento de repliegue en el barrio como respuesta a la crisis social. Si las transformaciones del mundo del trabajo y la crisis social convierten al barrio en refugio y terreno de socialización política e inscripción colectiva pues ofrece una identidad que ya no pasa por la afiliación política o profesional (Merklen, 2005), la literatura argentina se territorializa y vuelve al barrio, representado como el ámbito donde es posible la organización de solidaridades y cooperaciones, como base de la acción colectiva y fuente de identificación. Frente a la desarticulación del todo social, varias novelas presentaron espacios ligados al mundo de lo familiar, la infancia y lo privado, que buscaron reconstruir, en el plano de lo simbólico, ámbitos de pertenencia y redes de solidaridad por fuera de la violencia social. Así como en La Villa (2001) y Las noches de Flores (2004) de César Aira, el barrio y la villa miseria son escenarios de un mundo integrado, con reglas claras de convivencia y de solidaridad, en muchos textos escritos a partir de entonces, algunos barrios de la ciudad de Buenos Aires o del conurbano bonaerense se manifestaron como los ámbitos de reconstitución de las identidades colectivas (Hernaiz, 2006). Es el barrio de Boedo en las narraciones de Fabián Casas (Los Lemmings y otros, 2005; Ocio, 2006) y Constitución en las de Washington Cucurto (Cosa de negros, 2003; El curandero del amor, 2006); es Lanús (2002) de Sergio Olguín, Montserrat (2006) de Daniel Link; o Villa Celina (2007) de Juan Diego Incardona. Con nostalgia, en algunos casos; con distancia irónica, en otros, estas novelas exponen hipótesis sobre la sociedad a partir de la creación de espacios alternativos a la disolución del entramado social de los comienzos del siglo veintiuno. Se trata de una literatura preocupada por su contorno, del que da cuenta a través de tramas ancladas en ciertas zonas del territorio urbano.

Atenta al presente político y cultural como uno de los modos de volver a articular el diálogo con las principales problemáticas sociales que lo atraviesan, la narrativa argentina de comienzos del siglo veintiuno experimentó con géneros y procedimientos que son nuevos — sobre todo, a partir de la incorporación de discursos que provienen de soportes electrónicos como los blogs, los mails, los chats- pero sin renunciar por eso a su inscripción en las grandes tradiciones de la literatura argentina. Aun cuando los tiempos de la globalización, la postautonomía y las presiones del mercado editorial parecieran imponerse, la literatura argentina continúa pensándose en el diálogo, la confrontación o la 
tensión, con una tonalidad, una entonación, la fidelidad a ciertos espacios, que son constitutivos de lo que hoy se reconoce como literatura argentina. Porque, como decía Osvaldo Lamborghini, para los escritores argentinos, "Argentina no es ninguna raza ni nacionalidad, sino puro estilo y lengua" (Lamborghini, 1975).

\section{Bibliografía}

Aira, César (1981). "Novela argentina: nada más que una idea”. Vigencia 51. 55-58.

(1992). El llanto. Rosario: Beatriz Viterbo.

. (1993). Cómo me hice monja. Rosario: Beatriz Viterbo.

. (1998). El Congreso de literatura. Buenos Aires: Tusquets.

. (2001). La Villa. Buenos Aires: Emecé.

. (2003). El mago. Buenos Aires: Mondadori.

. (2004). Las noches de Flores. Barcelona: Mondadori.

Anguita, Eduardo y Martín Caparrós (1997-1998). La voluntad. Tres tomos. Buenos Aires: Norma.

Armony, Víctor y Gabriel Kessler (2004). "Imágenes de una sociedad en crisis. Cuestión social, pobreza y desempleo". Vicente Palermo y Marcos Novaro (compiladores). La historia reciente. Argentina en democracia. Buenos Aires: Edhasa.

Astutti, Adriana y Sandra Contreras (octubre-diciembre de2001). "Editoriales independientes, pequeñas... Micropolíticas culturales en la literatura argentina actual". Revista Iberoamericana 197, a. LXVII. 167-780.

Bizzio, Sergio (2005). Rabia. Buenos Aires: Interzona.

Bonasso, Miguel (1997). El presidente que no fue. Buenos Aires: Planeta.

Bruzzone, Félix (2008). Los topos. Buenos Aires: Mondadori.

Carrión, Jorge (editor). (2008). El lugar de Piglia. Crítica sin ficción. Barcelona: Candaya. 
Casanova, Pascale (2001). La República mundial de las letras. Barcelona: Anagrama.

Casas, Fabián (2005). Los Lemmings y otros. Buenos Aires: Santiago Arcos. . (2006). Ocio. Buenos Aires: Santiago Arcos.

Chejfec, Sergio (1999). Los planetas. Buenos Aires: Alfaguara.

Contreras, Sandra (2002). Las vueltas de César Aira. Rosario: Beatriz Viterbo.

. (2006). "Discusiones sobre el realismo en la narrativa argentina contemporánea". Orbis Tertius 12. 1-9.

Cucurto, Washington (2003). Cosa de negros. Buenos Aires: Interzona. . (2006). El curandero del amor. Buenos Aires: Emecé.

Dalmaroni, Miguel (2004). La palabra justa. Literatura, crítica y memoria en la Argentina (1960-2002). Santiago de Chile: Melusina / Ril editores.

De Diego, José Luis (2001). ¿Quién de nosotros escribirá el Facundo? Intelectuales y escritores en Argentina (1970-1986). La Plata: Ediciones Al Margen.

Demarchi, Rogelio (2003). De la crítica de la ficción a la ficción de la crítica. Córdoba: Municipalidad de Córdoba.

Di Marco, Jorge (2003). “Ficción y memoria en la narrativa argentina actual: la escritura como táctica". $V^{o}$ Congreso Internacional Orbis Tertius de Teoría y Crítica Literaria, 13 a 16 de agosto. URL: <http://www. fahce.unlp.edu.ar/congresos/orbis $>$.

Feijóo, Cristina (2001). Memorias del río inmóvil. Buenos Aires: Aguilar.

Ferreyra, Gustavo (2004). Vértice. Buenos Aires: Sudamericana.

Fogwill, Rodolfo (1998). Vivir afuera. Buenos Aires: Sudamericana. . (1998). Cantos de marineros en La Pampa. Barcelona: Mondadori. . (2000). La experiencia sensible. Buenos Aires: Mondadori. . (2001). En otro orden de cosas. Buenos Aires: Mondadori. 
Gambaro, Griselda (2004). Promesas y desvaríos. Buenos Aires: Norma.

Gamerro, Carlos (1998). Las Islas. Buenos Aires: Simurg. . (2004). La aventura de los bustos de Eva. Buenos Aires: Norma. . (27 de noviembre de 2005). "Una semana en la vida". Radarlibros, Página/12.

Gramuglio, María Teresa (diciembre de 2002). "Políticas del decir y formas de la ficción. Novelas de la dictadura militar". Punto de Vista 74. 9-14.

García Canclini, Néstor (2001). La globalización imaginada. Buenos Aires: Paidós.

Guebel, Daniel (2004). La vida por Perón. Buenos Aires: Emecé. . (1995). Villa. Buenos Aires: Alfaguara.

. (2002). Ni muerto has perdido de tu nombre. Buenos Aires: Sudamericana.

Heker, Liliana (1996). El fin de la historia. Buenos Aires: Alfaguara.

Hernaiz, Sebastián (diciembre de 2006). "Sobre lo nuevo: a cinco años del 19 y 20 de diciembre". El Interpretador 29. URL: <http:/ / www.elinterpretador.blogspot.com. $\operatorname{ar} / 2006 / 12 / 29 . h t m l>$.

Incardona, Juan Diego (2007). Villa Celina. Buenos Aires: Norma.

Jarkowski, Aníbal (2007). El trabajo, Buenos Aires: Tusquets.

Kohan, Martín (2002). Dos veces junio. Buenos Aires: Sudamericana. . (diciembre de 2005). "Significación actual del realismo críptico".

Boletín/12 del Centro de Estudios de Teoría y Crítica Literaria 24-35.

. (2007). Ciencias morales. Buenos Aires: Anagrama. . (2006). Museo de la revolución. Buenos Aires: Anagrama.

Laiseca, Alberto (1998). Los Soria, Buenos Aires: Simurg.

Lamborghini, Osvaldo (mayo de 1975). "La palabra fuera de lugar". Literal 2-3. 23-33. 
Link, Daniel (2003). "Literatura de compromiso". Foro Hispánico 24. La literatura argentina de los años 90. Amsterdam-New York: Rodopi. . (2006). Montserrat. Buenos Aires: Mansalva.

Longoni, Ana (2007). Traiciones. La figura del traidor en los relatos acerca de los sobrevivientes de la represión. Buenos Aires: Norma.

Martini, Juan (2002). Puerto Apache. Buenos Aires: Sudamericana.

Merklen, Denis (2005). Pobres ciudadanos Las clases populares en la era democrática (Argentina, 1983-2003). Buenos Aires: Gorla.

Olguín, Sergio (2002). Lanús. Buenos Aires: Norma.

Oloixarac, Pola (2008). Las teorías salvajes. Buenos Aires: Entropía.

Pauls, Alan (2007). Historia del llanto. Buenos Aires: Anagrama.

Piglia, Ricardo (1980). Respiración artificial. Buenos Aires: Pomaire. . (1988). Prisión perpetua. Buenos Aires: Sudamericana. . (1992). La ciudad ausente. Buenos Aires: Sudamericana. . (1997). Plata quemada. Buenos Aires: Planeta. . (1999). Formas breves. Buenos Aires: Temas de Grupo Editorial.

Premat, Julio (2003). "Saer fin de siglo y el concepto de lugar". Foro Hispánico 24. La literatura argentina de los años 90. Amsterdam-New York: Rodopi.

Prieto, Martín (1999). Calle de las Escuelas $N^{\circ} 13$. Buenos Aires: Perfil. Saer, Juan José (2001). Cuentos Completos. Buenos Aires: Seix Barral. . (2005). La grande. Buenos Aires: Seix Barral.

Sarlo, Beatriz (2005). Tiempo pasado. Cultura de la memoria y giro subjetivo. Buenos Aires: Siglo veintiuno. . (2007). "El tiempo inagotable". Escritos sobre literatura argentina. Buenos Aires: Siglo veintiuno, 317-320. . (2012). "Condición de búsqueda". Ficciones argentinas. 33 ensayos. Buenos Aires: Mardulce, 51-55. 
Schiffrin, André (2001), La edición sin editores. Las grandes corporaciones y la cultura, Santiago de Chile: Ediciones Trilce.

Silberstein, Silvia (2002). Bajo el mismo cielo. Buenos Aires: Sudamericana.

Sonderéguer, María (2001). "Los relatos sobre el pasado reciente en Argentina: una política de la memoria". Iberoamericana. América Latina, España, Portugal 1. 99-113.

Speranza, Graciela (diciembre de 2005). "Por un realismo idiota", Boletín/12 del Centro de Estudios de Teoría y Crítica Literaria. 1-11.

Vázquez, Karina Elizabeth (2009). Fogwill: realismo y mala conciencia, Buenos Aires: Circeto.

Verbistky, Horacio (1995). El vuelo. Buenos Aires: Planeta.

Vezzetti, Hugo (2002). Pasado y presente. Guerra, dictadura y sociedad en la Argentina. Buenos Aires: Siglo Veintiuno. 